\title{
Adsorption studies of etherdiamine onto modified sugarcane bagasses in aqueous solution
}

\author{
Karla Aparecida Guimarães Gusmão, Leandro Vinícius Alves Gurgel, \\ Tânia Márcia Sacramento Melo, Cornélio de Freitas Carvalho, Laurent Frédéric Gil* \\ Departamento de Química, Instituto de Ciências Exatas e Biológicas, Universidade Federal de Ouro Preto, Campus Universitário Morro do Cruzeiro, \\ 35400-000 Ouro Preto, Minas Gerais, Brazil
}

\section{A R T I C L E I N F O}

\section{Article history:}

Received 12 February 2013

Received in revised form

13 November 2013

Accepted 20 November 2013

Available online 9 January 2014

\section{Keywords:}

Adsorption

Etherdiamine Flotigam 2835

Modified sugarcane bagasse

Iron ore flotation

\begin{abstract}
A B S T R A C T
In this study sugarcane bagasse was modified with succinic anhydride and EDTA dianhydride to obtain SCB 2 and EB adsorbents, respectively. These adsorbents were used to remove etherdiamine, which is used for iron ore flotation from single aqueous solutions. The removal and recovery of etherdiamine is important for environmental and economic reasons due to its toxicity and high cost. The results demonstrated that adsorption of etherdiamine by SCB 2 and EB was better fitted by a pseudo-secondorder kinetic model than pseudo-first-order and Elovich models. Adsorption isotherms were better fitted by the Langmuir model rather than the Freundlich, Sips, and Temkin models. The maximum adsorption capacities $\left(Q_{\max }\right)$ of SCB 2 and EB for etherdiamine adsorption were found to be 869.6 and $1203.5 \mathrm{mg} / \mathrm{g}$, respectively. The calculated $\Delta G^{\circ}$ values for adsorption of etherdiamine on SCB $2(-22.70 \mathrm{~kJ} /$ $\mathrm{mol})$ and $\mathrm{EB}(-19.10 \mathrm{~kJ} / \mathrm{mol})$ suggested that chemisorption is the main mechanism by which etherdiamine is removed from the aqueous solution for both adsorbents. The high $Q_{\max }$ values showed that SCB 2 and EB are potential adsorbents for recovering the etherdiamine and treating effluents produced from iron ore flotation.
\end{abstract}

(c) 2013 Elsevier Ltd. All rights reserved.

\section{Introduction}

Brazil has the fifth largest reserve of iron ore in the world. With a high percentage of iron in iron ores, Brazil is among the largest producers and exporters of iron in the world (Alves, 2006). With the reduction in reserves of high-grade iron ore, concentration processes have become indispensable for mining companies that commercialize iron ore as a raw material to make steel (Filippov et al., 2010; Magriotis et al., 2010). Froth flotation is the most effective method from both the technological and economical points of view for iron ore beneficiation (Lima et al., 2005) and to upgrade the iron concentration (Filippov et al., 2010; Pearse, 2005). Although different flotation methods are available, reverse cationic flotation of quartz is by far the most widely used method to separate this major contaminant from iron ore (Araujo et al., 2005). Reverse cationic flotation of quartz is accomplished using fatty primary alkylamines partially neutralized with acetic acid, and basically consists of the selective separation of quartz particles from

\footnotetext{
* Corresponding author. Tel.: +55 313559 1717; fax: +55 3135591707.

E-mail address: laurent@iceb.ufop.br (L.F. Gil).
}

iron oxides (Lima et al., 2005). For this purpose, commercial organic amine salts, known as etheramines, are commonly used (Araujo et al., 2005). These compounds may have one or two amine groups and the overall chemical structure of such organic compounds is: $\left[\mathrm{R}-\mathrm{O}-\left(\mathrm{CH}_{2}\right)_{3}-\mathrm{NH}-\left(\mathrm{CH}_{2}\right)_{3}-\mathrm{NH}_{3}\right]^{+} \mathrm{CH}_{3} \mathrm{COO}^{-}$for etherdiamine and $\left[\mathrm{R}-\mathrm{O}-\left(\mathrm{CH}_{2}\right)_{3}-\mathrm{NH}_{3}\right]^{+} \mathrm{CH}_{3} \mathrm{COO}^{-}$for etheramine $(\mathrm{R}=$ alkyl group with carbon number $>10$ ), respectively (Araujo et al., 2010).

The presence of an ether group in the etheramine chain also increases its solubility in water (Lima et al., 2005). In the flotation process, the fatty amine is added to the system and is adsorbed on the quartz surface, and both are removed from the system as an aqueous pulp. However, at the $\mathrm{pH}$ at which this process occurs (close to 10 ), both quartz $\left(\mathrm{SiO}_{2}\right)$ and hematite $\left(\mathrm{Fe}_{2} \mathrm{O}_{3}\right)$ surfaces are positively charged, and therefore they can adsorb the amine despite its preferential attraction for quartz. In order to avoid competitive iron oxide flotation, starch is used as a depressing agent (Araujo et al., 2010).

Globally, iron ore processing consumes $15,000-20,000$ tons of etheramine, representing approximately 85 million US dollars (Magriotis et al., 2010). Due to its toxicity to aquatic organisms, high chemical oxygen demand (COD) value, corrosive proprieties and 
high cost, the removal and the possible reuse of this compound is important. The adsorption of etheramine onto efficient and low cost supports enables water recycling and the recovery of amines from the effluent, which could result in a considerable reduction in operating costs (Magriotis et al., 2010). In addition, the adsorption process could also help to decrease the amount of toxic etheramines discharged without any treatment into the environment (Magriotis et al., 2010).

Among the various methods available for water treatment, adsorption has received much attention since it not only reduces environmental contamination but also allows for water recycling and chemical recovery, which increases the feasibility of the process. At the present moment, few studies in the literature have investigated the adsorption of etheramines (Magriotis et al., 2010; Safa and Bhatti, 2011; Teodoro and Leão, 2004), and in both studies, clays were used as the solid support. No study of etheramine recovery has been performed yet.

Sugarcane bagasse is a residue from the sugarcane crushing process. It is composed of lignin (20-25\%), polyoses (25-30\%), cellulose (40-50\%); the minor components are extractives and ash (Caraschi et al., 1996). In the Brazilian scenario, the use of agricultural residues for novel applications is particularly attractive and a promising source of new materials, given that the investments made by local industries in recent years for the production of renewable fuels continue to grow. According to the Brazilian Ministry of Agriculture, the sugarcane harvest in the 2011/2012 season is expected to reach 571.4 million tons, which will generate about 142.9 million tons of bagasse and 116.6 million tons of straw (CONAB, 2011). The macromolecules present in sugarcane bagasse, through their hydroxyl groups, are able to chemically react to produce new materials with new properties (Navarro et al., 1996; Xiao et al., 2001). Various studies on the use of bagasse as adsorbent for the removal of various pollutants can be found in the literature (Crini, 2006; Gupta and Suhas, 2009; Gurgel and Gil, 2009; Ho et al., 2005; Karnitz et al., 2007; Kumar, 2006; Ngah and Hanafiah, 2008; Xing and Deng, 2009); however, at the present moment, none have investigated etheramine adsorption.

In our previous studies (Gurgel et al., 2008; Gusmao et al. 2012; Karnitz et al., 2009, 2010; Pereira et al., 2009; Pereira et al., 2010), sugarcane bagasse modified with succinic anhydride (SCB 2) and with EDTAD (EB) were used as adsorbent materials for heavy metal and cationic dye adsorption. Both adsorbent materials (SCB 2 and EB) present a negatively charged surface due to the presence of carboxylate groups that are released after modification with succinic and EDTAD anhydrides and treatment with sodium bicarbonate solution. These charges are able to interact with cationic species such as dyes and heavy metals among others. At $\mathrm{pH} 10$, about $50 \%$ of etheramine is in the ionized form and $50 \%$ is in the non-ionized form (Leja, 1982). Thus, at pH levels lower than 10 , etheramines are positively charged (protonated) and can interact with negatively charged solid supports as SCB 2 and EB.

In the present study, the removal of the etherdiamine Flotigam 2835 by adsorption from aqueous solution using SCB 2 and EB was extensively investigated with the aim of evaluating the possibility of applying SCB 2 and EB to the treatment of effluents containing etheramines from iron ore mining. SCB 2 and EB were chosen as the adsorbents due to their vast range of possible industrial applications including the treatment of effluents from textile and plating industries and from acid mine drainage. The adsorption studies were carried out using different contact times, $\mathrm{pH}$ values, and initial etherdiamine concentrations. The results were evaluated by different kinetic and adsorption models.

\section{Materials and methods}

\subsection{Materials}

Sugarcane bagasse was collected from a local alcohol and sugar plant in the city of Ouro Preto, Minas Gerais, Brazil. Succinic anhydride and pyridine were purchased from Vetec (Brazil). Pyridine was left under reflux overnight with $\mathrm{NaOH}$ and then distilled. $\mathrm{N}, \mathrm{N}$ Dimethylformamide (DMF) was purchased from Synth (Brazil) and distilled under reduced pressure before use. EDTA (disodium salt) and acetic anhydride were purchased from Synth (Brazil) and used without further purification. Etherdiamine Flotigam 2835 ([R-O$\left.\left(\mathrm{CH}_{2}\right)_{3}-\mathrm{NH}-\left(\mathrm{CH}_{2}\right)_{3}-\mathrm{NH}_{3}\right]^{+} \mathrm{CH}_{3} \mathrm{COO}^{-}$with $\mathrm{R}=$ alkyl chain with carbon numbers of 12 (20\%) and 13 (80\%), respectively) was produced and distributed by the Clariant ${ }^{\circledR}$ company (São Paulo, SP, Brazil).

\subsection{Sugarcane bagasse preparation}

First, sugarcane bagasse was dried in sunlight. The bagasse stalks were manually broken to reduce their length and then dried in an oven at $90{ }^{\circ} \mathrm{C}$ for $24 \mathrm{~h}$. After that, it was pulverized in a vibratory disc mill equipped with tungsten carbide. The powder was sifted in a four-sieve system composed of screens of 10 $(1.68 \mathrm{~mm}), 60(0.251 \mathrm{~mm}), 100(0.152 \mathrm{~mm})$ and $200(0.075 \mathrm{~mm})$ mesh. The fraction between 100 and 200 mesh was collected and washed at first with hot distilled water at $60-70{ }^{\circ} \mathrm{C}$ for $1 \mathrm{~h}$ to eliminate the residual sugars and then washed with 95\% EtOH and dried at $90{ }^{\circ} \mathrm{C}$ in an oven. Finally, this fraction was washed in a Soxhlet apparatus with hexane-ethanol $(1: 1, \mathrm{v}: \mathrm{v})$ for $4 \mathrm{~h}$ and then dried at $90^{\circ} \mathrm{C}$ in an oven to remove the organic solvents and stored in a desiccator prior to use.

\subsection{Preparation of SCB 2}

SCB 2 was prepared and characterized according to the methodology described by Gurgel et al. (2008). Sugarcane bagasse (5 g), succinic anhydride $(15 \mathrm{~g})$, and anhydrous pyridine $(50 \mathrm{~mL})$ were added to a round-bottom flask equipped with a reflux condenser. The mixture was heated under pyridine reflux for $24 \mathrm{~h}$. At the end of the succinylation reaction, modified bagasse was separated by filtration using a sintered glass funnel (porosity 3), washed with a solution of acetic acid in methylene chloride $(1 \mathrm{~mol} / \mathrm{L})$, ethanol (95\%), distilled water, saturated sodium bicarbonate solution, distilled water, and finally with acetone. SCB 2 was dried in an oven at $90{ }^{\circ} \mathrm{C}$ for $1 \mathrm{~h}$.

\subsection{Preparation of EB}

EDTA dianhydride was prepared using the methodology described by Karnitz et al. (2009) using EDTA disodium salt and acetic anhydride. EDTA disodium (50.0 g) was dissolved in a $1000 \mathrm{~mL}$ beaker containing $500 \mathrm{~mL}$ of distilled water. Concentrated $\mathrm{HCl}$ was added drop by drop until the precipitation of $\mathrm{H}_{4}$ EDTA occurred. The precipitate was vacuum filtered and rinsed in $95 \%$ $\mathrm{EtOH}$, diethyl ether and subsequently dried in an oven for $2 \mathrm{~h}$ at $105^{\circ} \mathrm{C}$ and cooled in a desiccator prior to use. For the preparation of EDTA dianhydride, $18.0 \mathrm{~g}$ of $\mathrm{H}_{4}$ EDTA was suspended in $31 \mathrm{~mL}$ of anhydrous pyridine in a $250 \mathrm{~mL}$ round-bottom flask and $24 \mathrm{~mL}$ of acetic anhydride were added to the suspension. A reflux condenser was attached to the flask and the mixture was heated at $65{ }^{\circ} \mathrm{C}$ and kept under constant magnetic stirring for $24 \mathrm{~h}$. After the reaction time, the solid (EDTA dianhydride) was vacuum filtered, rinsed in diethyl ether and stored in a desiccator under reduced pressure prior to use. 
The functionalization of sugarcane bagasse with EDTA dianhydride was performed according to the method described by Karnitz et al. (2009). Sugarcane bagasse (B) (1 g) and EDTA dianhydride ( $3 \mathrm{~g}$ ) were added to a $250 \mathrm{~mL}$ round-bottom flask with $42 \mathrm{~mL}$ of anhydrous DMF. The suspension was heated at $75{ }^{\circ} \mathrm{C}$ and soft stirred for $24 \mathrm{~h}$. At the end of the reaction, the suspension was vacuum filtered using a sintered glass funnel (porosity 3) and rinsed in DMF, distilled water, saturated solution of sodium bicarbonate, distilled water, and finally with $95 \% \mathrm{EtOH}$. After that, the modified sugarcane bagasse (EB) was dried in an oven at $100{ }^{\circ} \mathrm{C}$ for $1 \mathrm{~h}$ and stored in a desiccator prior to use.

\subsection{Characterization of the $S C B 2$ and $E B$}

\subsubsection{Weight percent gain (wpg)} (1):

The weight percent gain (wpg) was calculated according to Eq.

$w p g, \%=\left(\frac{w_{\text {mod }}-w_{\text {unmod }}}{w_{\text {unmod }}}\right) \times 100$

where $w_{\text {mod }}$ is the weight of modified bagasse and $w_{\text {unmod }}$ is the weight of unmodified bagasse.

\subsubsection{Number of free carboxylic acid groups $\left(n_{\mathrm{COOH}}\right)$}

The number of free carboxylic acid groups $\left(n_{\mathrm{COOH}}\right)$ in SCB 2 (in acid form) was determined by acid-base back titration of the carboxylic acid functions released after the succinylation reaction of $\mathrm{B}$ (Karnitz et al., 2007). The number of free carboxylic functions per gram of adsorbent material was calculated using Eq. (2) as follows.

$n_{\mathrm{COOH}}, \mathrm{mmol} / \mathrm{g}=\left(\frac{C_{\mathrm{NaOH}} V_{\mathrm{NaOH}}-4 C_{\mathrm{HCl}} V_{\mathrm{HCl}}}{m_{\mathrm{ads}}}\right) \times 100$

where $C_{\mathrm{NaOH}}(\mathrm{mmol} / \mathrm{L})$ is the concentration of the $\mathrm{NaOH}$ solution, $C_{\mathrm{HCl}}(\mathrm{mmol} / \mathrm{L})$ is the concentration of the $\mathrm{HCl}$ solution, $V_{\mathrm{NaOH}}(\mathrm{L})$ is the volume of the $\mathrm{NaOH}$ solution, $V_{\mathrm{HCl}}(\mathrm{L})$ is the volume of $\mathrm{HCl}$ spent in the titration of excessive non-reacted $\mathrm{NaOH}$, and $m_{\mathrm{ads}}(\mathrm{g})$ is the weight of adsorbent material.

\subsubsection{FTIR analysis}

The samples were prepared by mixing $1 \mathrm{mg}$ of each material with $100 \mathrm{mg}$ of spectroscopy grade $\mathrm{KBr}$. The FTIR spectra were recorded using Nicolet Impact 410 equipment with the detector at a resolution of $4 \mathrm{~cm}^{-1}$ from 400 to $4000 \mathrm{~cm}^{-1}$ and 32 scans per sample.

\subsubsection{Elemental analysis}

The adsorbent materials were previously washed with acetone and dried at $90{ }^{\circ} \mathrm{C}$ for $1 \mathrm{~h}$ before analysis. The elemental analyses were accomplished using a Perkin Elmer Series II CHNS/O Model 2400 analyzer.

\subsubsection{Determination of the point of zero charge ( $\mathrm{pH}_{P Z \mathrm{C}}$ )}

The $\mathrm{pH}$ of the point of zero charge $\left(\mathrm{pH}_{P Z C}\right)$ of SCB 2 and EB were determined using the mass titration (MT) method described by Noh and Schwarz (Noh and Schwarz, 1990). Sodium nitrate $\left(\mathrm{NaNO}_{3}\right)$ solutions with $\mathrm{pH}$ values of 3,6 , and 9 were prepared using $0.1 \mathrm{~mol} /$

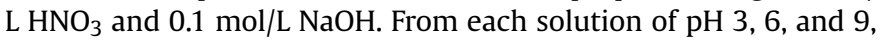
six aliquots of $20 \mathrm{~mL}$ were taken and transferred to $50 \mathrm{~mL}$ Erlenmeyer flasks. Then, different amounts of SCB 2 and EB were added to Erlenmeyer flasks to give suspensions of $0.05,0.1,0.5,1.5$, and $10 \%$. The equilibrium $\mathrm{pH}$ was measured using a $\mathrm{pH}$ meter after $4 \mathrm{~h}$ of shaking at $25^{\circ} \mathrm{C}$.

\subsubsection{BET surface area and pore size}

The experiments to obtain the surface area, volume and width of the micropores of SCB 2 and EB were carried out using a NOVA ${ }^{\circledR}$ Surface Area Analyzer model 1000 (Quantachrome Instruments).

\subsubsection{Scanning electron microscopy (SEM)}

The morphology of the SCB 2 and EB adsorbents before and after adsorption of etherdiamine (Flotigam 2835) was examined with a Vega3 SB (Tescan/Oxford Instruments) scanning electron microscope, using a filament voltage of $20 \mathrm{keV}$. The samples of SCB 2 and EB containing etherdiamine adsorbed were dried in an oven at $45^{\circ} \mathrm{C}$ for $8 \mathrm{~h}$ in order to avoid the degradation of etherdiamine. Dry powder samples were dispersed on a graphite ribbon fixed on an aluminum sample holder. The powders were sputter-coated with gold in a modular high-vacuum coating system Q150R ES (Quorum Technologies).

\subsection{Characterization of etherdiamine}

The structural characterization of etherdiamine was performed using an electrospray ionization mass spectrometer (model IT-TOF, Shimadzu, Tokyo, Japan) with two analyzers in tandem: ion trap (IT) and time-of-flight (TOF). The mass spectrometer operating at high resolution and mass accuracy $(<5 \mathrm{ppm})$ was optimized under the following conditions: ESI voltage at $+4.5 \mathrm{kV}$ (positive ion mode); nebulizer gas (nitrogen) flow rate at $1.5 \mathrm{~L} / \mathrm{min}$; curved desorption line (CDL) interface temperature at $200{ }^{\circ} \mathrm{C}$; drying gas (nitrogen) pressure at $100 \mathrm{kPa}$; octapole ion accumulation time of $10 \mathrm{~ms}$. Mass spectra were obtained in the full scan mode within an $\mathrm{m} / \mathrm{z}$ range from 100 to 1000 .

\subsection{Adsorption experiments}

The adsorbent materials SCB 2 and EB were used for etherdiamine (Flotigam 2835) adsorption in aqueous solutions in batch adsorption mode. All the adsorption experiments were performed at $25^{\circ} \mathrm{C}$. The adsorption data were modeled by several kinetic and isotherm models.

\subsubsection{Kinetic study of adsorption of etherdiamine onto SCB 2 and $E B$}

Samples of $25.0 \mathrm{mg}$ of SCB 2 or EB were weighed and added to $250 \mathrm{~mL}$ Erlenmeyer flasks containing $50.0 \mathrm{~mL}$ of etherdiamine solution of a known concentration $(450.0 \mathrm{mg} / \mathrm{L})(\mathrm{pH} 8)$. After the contact of the adsorbent with etherdiamine solution the $\mathrm{pH}$ of the suspensions was measured during the experiment and no significant changes in $\mathrm{pH}$ were noticed. The Erlenmeyer flasks were shaken at a constant speed ( $150 \mathrm{rpm})$ at $25{ }^{\circ} \mathrm{C}$ for different time intervals $(10,20,30,45,60,90,120,150$, and $200 \mathrm{~min})$. At the end of each experiment, the sample was subjected to centrifugation (Excelsa ${ }^{\circledR}$ II centrifuge, Model $206 \mathrm{BL}$ ) at $3600 \mathrm{rpm}$ for $20 \mathrm{~min}$ to separate the solid and liquid phases. The residual concentration of etherdiamine in the supernatant phase was determined by chemical oxygen demand (COD) (Clesceri et al., 1995). This procedure was based on the same reaction used for determination of COD. Such procedure consists in the oxidation of organic compounds with $\mathrm{K}_{2} \mathrm{Cr}_{2} \mathrm{O}_{7}$ in sulfuric acid medium at high temperature $\left(148^{\circ} \mathrm{C}\right)$ using $\mathrm{Ag}_{2} \mathrm{SO}_{4}$ as a catalyst. The concentration of etherdiamine is directly proportional to the concentration of $\mathrm{Cr}^{3+}$ formed in the oxidation of etherdiamine. The concentration of $\mathrm{Cr}^{3+}$ was measured on an UV-Vis spectrophotometer (BioSpectro, SP-220) at $600 \mathrm{~nm}$. Standard aqueous solutions of etherdiamine were prepared and oxidized using the above procedure to build a calibration curve from which the equilibrium concentration of etherdiamine was calculated. The limit of detection of the method is $7.9 \mathrm{mg} / \mathrm{L}$. The precision of the method is $2.0 \%$. 
The amount of etherdiamine adsorbed on SCB 2 or EB in each period of time was calculated using Eq. (3).

$q_{t}, \mathrm{mg} / \mathrm{g}=\frac{\left(C_{i}-C_{t}\right) V}{w_{\mathrm{ads}}}$

where $q_{t}(\mathrm{mg} / \mathrm{g})$ is the amount of etherdiamine adsorbed per weight of SCB 2 or EB at a time $t, V(\mathrm{~L})$ is the volume of the etherdiamine solution, $C_{i}(\mathrm{mg} / \mathrm{L})$ is the initial concentration of etherdiamine, $C_{t}(\mathrm{mg} / \mathrm{L})$ is the concentration of etherdiamine at time $t$, and $w_{a d s}(\mathrm{~g})$ is the weight of the adsorbent material.

\subsubsection{Adsorption as a function of $\mathrm{pH}$}

In order to evaluate the effect of $\mathrm{pH}$ on the adsorption of etherdiamine on modified adsorbents, samples of $25.0 \mathrm{mg}$ of SCB 2 or EB were weighed and added to $250 \mathrm{~mL}$ Erlenmeyer flasks containing $50.0 \mathrm{~mL}$ of etherdiamine solution of a known concentration ( $450.0 \mathrm{mg} / \mathrm{L}$ ). The $\mathrm{pH}$ of the suspensions was adjusted to values between 2 and 10 by adding few drops of aqueous $\mathrm{HCl}$ and $\mathrm{NaOH}$ solutions $(0.01-0.1 \mathrm{~mol} / \mathrm{L})$. The $\mathrm{pH}$ of the suspensions was measured during the experiment and no significant changes in $\mathrm{pH}$ were noticed. If small changes in $\mathrm{pH}$ occurred they were immediately corrected. The Erlenmeyer flaks were shaken at a constant speed (150 rpm) until the equilibrium time was reached (180 min). After shaking, the samples were subjected to centrifugation at $3600 \mathrm{rpm}$ for $20 \mathrm{~min}$ to separate the solid and liquid phases. The final concentration of the etherdiamine solution in the supernatant was determined by COD (see Section 2.7.1). The amount of etherdiamine adsorbed on SCB 2 or EB at each pH was calculated according to Eq. (3).

\subsubsection{Adsorption isotherms}

Adsorption experiments as a function of the initial concentration of etherdiamine on SCB 2 or EB were performed to determine the adsorption isotherms. Samples of SCB 2 or EB $(25.0 \mathrm{mg})$ were weighed and added to $250 \mathrm{~mL}$ Erlenmeyer flasks containing $50.0 \mathrm{~mL}$ of etherdiamine solution of a known concentration in the range of $250-650 \mathrm{mg} / \mathrm{L}$. The experiments were performed at $\mathrm{pH} 10$ during the time required to reach equilibrium $(180 \mathrm{~min})$. The Erlenmeyer flaks were also shaken at a constant speed (150 rpm). The $\mathrm{pH}$ was adjusted to the optimum value for adsorption by adding few drops of aqueous $\mathrm{HCl}$ and $\mathrm{NaOH}$ solutions ranging from 0.01 to $0.1 \mathrm{~mol} / \mathrm{L}$. The $\mathrm{pH}$ of the suspensions was measured during the experiment and no significant changes in $\mathrm{pH}$ were noticed. If small changes in $\mathrm{pH}$ occurred they were immediately corrected. The etherdiamine concentration was determined as described in the Section 2.7.1. The amount of etherdiamine adsorbed on SCB 2 or EB was calculated according to Eq. (3).

\subsection{Extraction process of etherdiamine}

SCB 2 and EB containing adsorbed etherdiamine were recovered by a single filtration after adsorption experiments. These materials were used to evaluate the extraction process in order to recovery both etherdiamine and adsorbent materials. For this, the materials were separately treated three times with chloroform as the extraction solvent for 15 min and then the organic solvent was evaporated using a rotary evaporator. The extracted etherdiamine was weighed and the percentage of extraction was calculated using Eq. (4):

Extraction, $\%=\left(\frac{w_{\text {extracted }}}{Q_{\max } w_{\text {ads }}}\right) \times 100$

where $Q_{\max }$ is the maximum adsorption capacity determined by the Langmuir isotherm model $(\mathrm{mg} / \mathrm{g}), w_{\text {ads }}(\mathrm{g})$ is the weight of the adsorbent (SCB 2 or EB) containing adsorbed etherdiamine, and $w_{\text {extracted }}$ is the weight of etherdiamine extracted $(\mathrm{mg})$ from SCB 2 or EB.

\subsection{Free energy of adsorption}

According to Liu (2009), the Gibbs free energy change $\left(\Delta G^{\circ}\right)$ indicates the degree of spontaneity of an adsorption process. $\Delta G^{\circ}$ of adsorption is calculated using Eq. (5):

$\Delta G^{\circ}=-R T \ln K_{a}$

where $R$ is the gas constant $8.314 \mathrm{~J} / \mathrm{K} \mathrm{mol}, T(\mathrm{~K})$ is the absolute temperature, and $K_{a}$ is the thermodynamic equilibrium constant without units. Liu (2009) demonstrated that the relationship between the Langmuir equilibrium constant, $K_{L}$, and the thermodynamic equilibrium constant, $K_{a}$, can be given by Eq. (6):

$K_{a}=\left[\frac{K_{L}}{\gamma_{e}} \times(1 \mathrm{~mol} / L)\right]$

$\gamma_{e}$ is a function of the ionic strength $\left(I_{e}\right)$ of the solute at adsorption equilibrium and the charge carried by the solute $(z)$ (Debye-Hückel law). According to the Liu (2009) approach for neutral adsorbates or adsorbates with weak charges, Eq. (6) turns into Eq. (7):

$\Delta G^{\circ} \approx-R T \ln \left[K_{L} \times(1 \mathrm{~mol} / \mathrm{L})\right]=-R T \ln K_{L}$

This approach implies that for adsorbates with a weak charge, e.g. organic compounds such as dye molecules, the Langmuir equilibrium constant with units of $\mathrm{L} / \mathrm{mol}$ can be reasonably used for the determination of $\Delta G^{\circ}$. A detailed reading of Liu's discussion is strongly recommended by the authors to avoid erroneous use of this approach in the calculation of $\Delta G^{\circ}$.

\section{Results and discussion}

\subsection{Preparation and characterization of SCB 2 and $E B$}

The succinylation reaction of $\mathrm{B}$ (Fig. 1a) allowed the introduction of chelating functions to sugarcane bagasse by the esterification of hydroxyl groups with succinic anhydride. The weight gain and number of free carboxylic acid groups per gram of SCB 2 were found to be $80.5 \%$ and $6.0 \mathrm{mmol} / \mathrm{g}$, respectively. SCB 2 was also characterized by FTIR spectroscopy (Fig. 2). The most important changes that could be noted were the newly arising band at $2925 \mathrm{~cm}^{-1}$, corresponding to asymmetric stretching of $\mathrm{CH}_{2}$ due to the introduction of the succinyl group, at 1577 and $1419 \mathrm{~cm}^{-1}$, corresponding to asymmetric and symmetric stretching owing to the presence of carboxylate functions $\left(-\mathrm{COO}^{-} \mathrm{Na}^{+}\right)$, and at $1743 \mathrm{~cm}^{-1}$, corresponding to asymmetric and symmetric stretching of ester groups $(-\mathrm{C}-\mathrm{O}-\mathrm{C}=\mathrm{O})$ owing to the introduction of the succinyl group by esterification.

The treatment of sugarcane bagasse (B) with EDTA dianhydride (EDTAD) in DMF at $75{ }^{\circ} \mathrm{C}$ for $24 \mathrm{~h}$ furnished the modified material $\mathrm{EB}$, as can be seen in Fig. 1a. Based on the nitrogen content determined by elemental analysis, the number of EDTA units introduced to the sugarcane bagasse after the esterification of hydroxyl groups was assessed. The results show that EB was obtained with a weight gain of $50.7 \%$ and elemental analysis of EB presented a nitrogen content of $2.32 \%$. The nitrogen content was used to estimate the amount of EDTAD introduced into EB. This calculation demonstrated that $0.786 \mathrm{mmol}$ of EDTAD were introduced per gram of EB. There was a considerable increase in the nitrogen content after modification with EDTA dianhydride (the nitrogen content of B was 
(a)

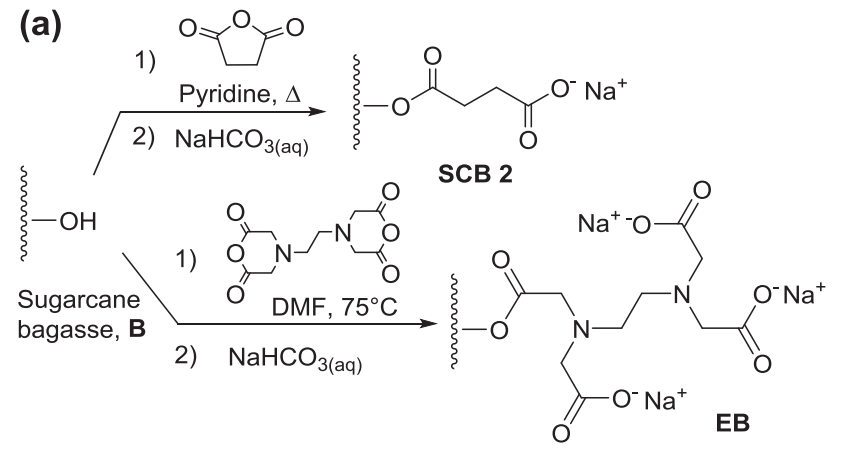<smiles></smiles>

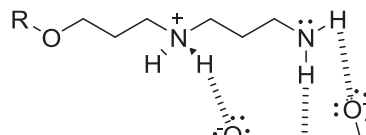<smiles>O=C(O)CN1CCOC1=O</smiles>

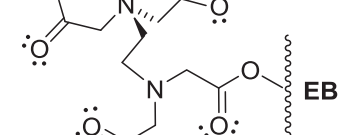<smiles>[R]OCCCNCCCNNCOCCOC(=O)CC</smiles>

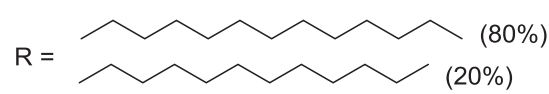

Fig. 1. (a) Synthesis route used to obtain SCB 2 and EB and (b) suggested mechanism for the adsorption of etherdiamine Flotigam 2835 on SCB 2 and EB.

$0.13 \%$ ) with a significant weight gain, which proves the success of the reaction and the incorporation of amine functions in the modified sugarcane bagasse (EB). The FTIR spectra of bagasse before (B) and after modification with EDTA dianhydride are shown in Fig. 2. The two major changes noted in the FTIR spectra for EB in comparison with the unmodified starting material (B) were (1) a strong band at $1741 \mathrm{~cm}^{-1}$, corresponding to asymmetric and symmetric stretching of $\mathrm{C}-\mathrm{O}$ from ester groups and (2) strong bands at 1633,1602 , and $1406 \mathrm{~cm}^{-1}$, corresponding to asymmetric and symmetric stretching due to presence of the carboxylate ion. The ester and carboxylate bands indicate that EDTAD was introduced via the formation of ester linkages with the consequent release of carboxylic functional groups (Karnitz et al., 2009; Pereira et al., 2010).

By modeling the adsorption of gases in the porous materials, it was possible to evaluate various characteristics of porous solids such as surface area, pore volume, and pore width. Obtaining these parameters is important since they are related to the sites available for adsorption. Table 1 summarizes the textural properties of SCB 2 and EB before the adsorption experiments. Their BET surface areas were very small in comparison with other adsorbents such as activated carbons, but with large total pore volume values indicating that functionalization of the sugarcane bagasse for the purposes of chemical adsorption experiments was effective.
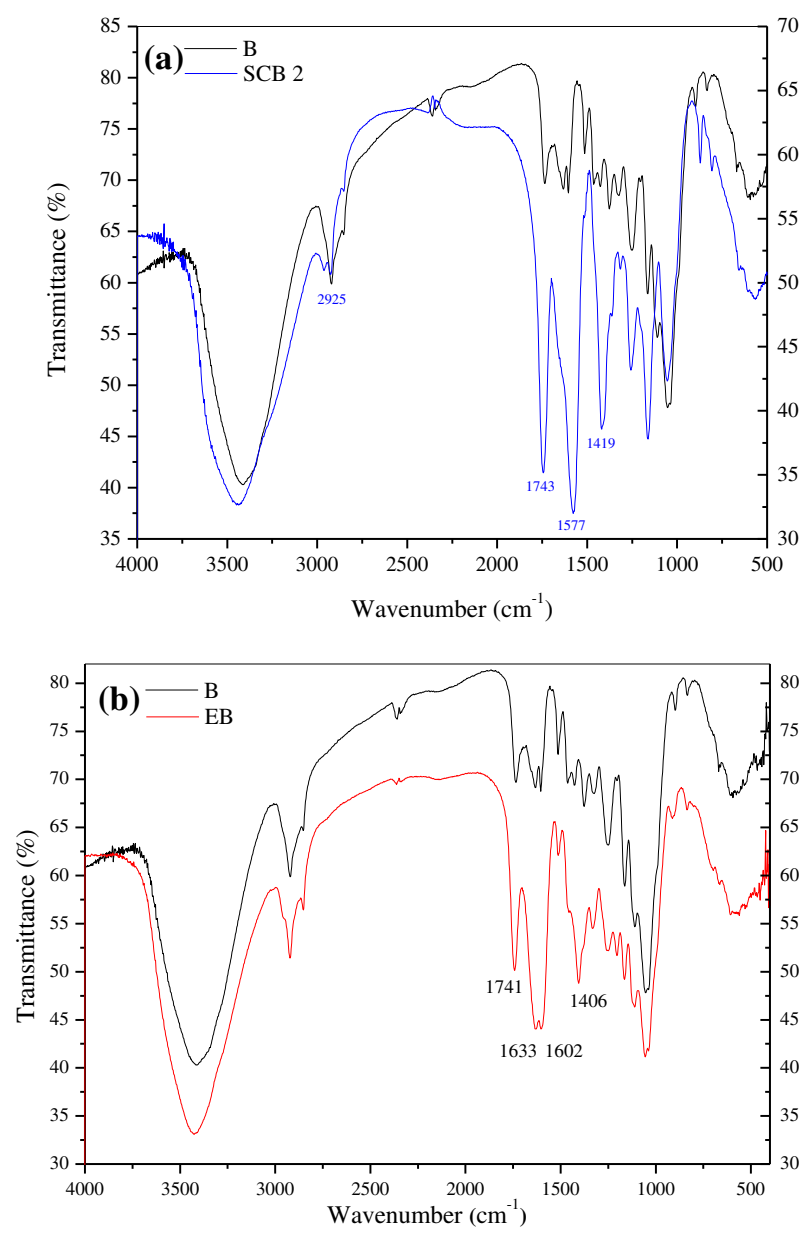

Fig. 2. FTIR spectra of SCB 2 (a) and EB (b).

The experimental titration curves (Figures not shown) for evaluation of point of zero charge $\left(\mathrm{pH}_{P Z C}\right)$ for $\mathrm{SCB} 2$ and $\mathrm{EB}$ converged to $\mathrm{pH}_{P Z C}$ values of 5.3 and 7.5 , respectively. Therefore $\mathrm{pH}$ values over 5.3 and 7.5 should ensure a predominantly negatively charged surface for SCB 2 and EB, respectively. These results suggest that when the $\mathrm{pH}$ of the etherdiamine solution is higher than $\mathrm{pH}_{P Z C}$ of SCB 2 and EB, these adsorbents have a negatively charged surface that can attract positively charged etherdiamine more efficiently as suggested in Fig. 1b. The adsorption of etherdiamine Flotigan 2835 was indeed favored at $\mathrm{pH}$ values higher than $\mathrm{pH}_{P Z C}$ of SCB 2 (5.3) and EB (7.5) as will be discussed in Section 3.3.2 (see Fig. 4).

\subsection{Characterization of etherdiamine}

The obtained mass spectra (Supplementary Fig. 1) for etherdiamine Flotigam 2835 (F 2835) showed peaks with $m / z$ ratios of 301 and 315 , respectively. According to Supplementary Fig. 1, it was possible to conclude that $\mathrm{F} 2835$ is composed of a mixture of etherdiamines $\left(\mathrm{R}-\mathrm{O}-\left(\mathrm{CH}_{2}\right)_{3}-\mathrm{NH}-\left(\mathrm{CH}_{2}\right)_{3}-\mathrm{NH}_{2}\right)$ with alkyl groups (R) containing $12(20 \%)$ or $13(80 \%)$ carbon atoms (Araujo et al., 2008).

Table 1

Textural properties of SCB 2 and EB materials.

\begin{tabular}{llll}
\hline Material & $\begin{array}{l}\text { BET surface } \\
\text { area }\left(\mathrm{m}^{2} \mathrm{~g}^{-1}\right)\end{array}$ & $\begin{array}{l}\text { Total pore volume } \\
\left(\mathrm{cm}^{3} \mathrm{~g}^{-1}\right)\end{array}$ & $\begin{array}{l}\text { Average pore } \\
\text { diameter }(\AA)\end{array}$ \\
\hline SCB 2 & 2.7 & 10.0 & 155.0 \\
EB & 1.5 & 4.0 & 108.0 \\
\hline
\end{tabular}




\subsection{Adsorption studies}

The adsorption properties of SCB 2 and EB were investigated by measuring the amount of adsorbed etherdiamine at different contact times, $\mathrm{pH}$ values, and etherdiamine initial concentrations.

\subsubsection{Effect of contact time}

Experiments to investigate the effect of contact time on the adsorption of etherdiamine on SCB2 and EB were carried out to determine the adsorption equilibrium time $\left(t_{e}\right)$. The effect of contact time on the adsorption of etherdiamine on SCB 2 and EB for a known initial etherdiamine concentration ( $450 \mathrm{mg} / \mathrm{L})$ at a $\mathrm{pH}$ equal to 8 at $25^{\circ} \mathrm{C}$ is shown in Fig. 3. As can be seen in Fig. 3, $t_{e}$ was attained after 90 min for both adsorbent materials. Magriotis et al. (2010) found equilibrium times of $30 \mathrm{~min}$ for the adsorption of etheramine Flotigam EDA (Clariant, São Paulo, SP, Brazil) on pink kaolinite.

\subsubsection{Effect of $p H$}

One of the most important parameters that directly affect the adsorption of etherdiamine on ionized superficies is the $\mathrm{pH}$. The dependence of etherdiamine uptake on $\mathrm{pH}$ is related to the $p K_{\mathrm{a}}$ of functional groups on the surface of the adsorbent material and the protonated forms of the nitrogen species (etherdiamine) in the solution. The adsorption of etherdiamine on SCB 2 and EB as function of $\mathrm{pH}$ is shown in Fig. 4.

The determination of the $p K_{a}$ of $N$-alkyl-1,3-diaminopropane with 12 carbon atoms in the aliphatic chain has done by Scott and Smith (1991). These authors found values of $p K a_{1}$ and $p K a_{2}$ equal to 6.8 and 9.3, respectively. The difference between etherdiamine Flotigam $2835\left(\mathrm{R}-\mathrm{O}-\left(\mathrm{CH}_{2}\right)_{3}-\mathrm{NH}-\left(\mathrm{CH}_{2}\right)_{3}-\mathrm{NH}_{3}^{+}\right)$and $\mathrm{N}$ alkyl-1,3-diaminopropane $\left(\mathrm{CH}_{3}-\left(\mathrm{CH}_{2}\right)_{11}-\mathrm{NH}-\left(\mathrm{CH}_{2}\right)_{3}-\mathrm{NH}_{3}^{+}\right)$is the presence of an oxygen as a heteroatom in the chemical structure of etherdiamine. However, the oxygen atom is three methylene groups away from the first amine group. At this distance, the electron withdrawing effect of the oxygen atom should not cause any pronounced effect on the basicity of the amine group. Therefore, it is possible to make an analogy between the $p K_{a}$ values of $N$ alkyl-1,3-diaminopropane determined by Scott and Smith (1991) with etherdiamine Flotigam 2835 in order to improve the discussion.

At $\mathrm{pH}$ lower than 9.3, at least one amine group is protonated and therefore positively charged and consequently negatively charged supports are able to interact with them. As can be seen in Fig. 4, the

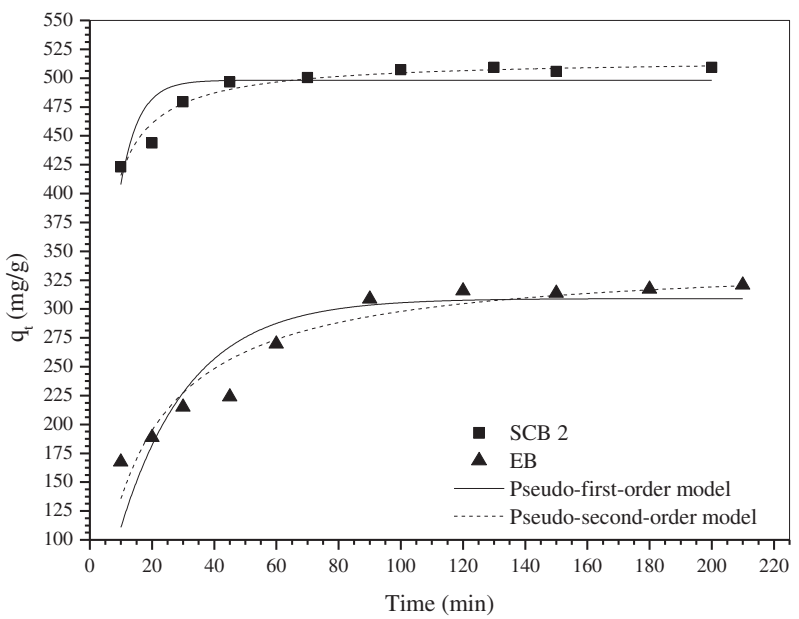

Fig. 3. Effect of contact time on the adsorption of etherdiamine on SCB 2 and EB. adsorption of etherdiamine on both materials increased as the $\mathrm{pH}$ increased. By increasing the $\mathrm{pH}$, the carboxylic acid groups from both materials become deprotonated and the adsorption capacity of positively charged etherdiamine is consequently increased. A similar tendency was noted by Magriotis et al. (2010) for the adsorption of etheramine on kaolinites. At lower $\mathrm{pH}$ values, the adsorption capacity of SCB 2 decreased following a linear tendency until it reached a very low value. In the case of $\mathrm{EB}$, the adsorption capacity reached a minimum plateau at approximately $\mathrm{pH} 6$. The greater adsorption capacity of EB in relation to SCB 2 at low pH values was attributed to the chemical properties of iminoacetate groups from EDTA ( $p K_{a}$ values of 0.0, 1.5, 2.0, and 2.69) (Dean and Lange, 1999), which have lower $p K_{a}$ values than succinyl groups ( $p K_{a}$ values of 3.5 and 4.5) (Dean and Lange, 1999). The low $p K_{\mathrm{a}}$ values of the iminoacetate groups make it possible for EB to adsorb protonated etherdiamine at low $\mathrm{pH}$ values, which gives the EB adsorbent material special adsorption properties. Fig. 1b shows the suggested mechanism for etherdiamine adsorption on SCB 2 and EB. Based on the results for the adsorption of etherdiamine on SCB 2 and $\mathrm{EB}$ as a function of $\mathrm{pH}$, a $\mathrm{pH}$ value of 10.0 was selected for both adsorbent materials to perform adsorption studies as a function of the initial etherdiamine concentration and to build the adsorption isotherms.

\subsection{Adsorption isotherms}

The adsorption isotherms of SCB 2 and EB were obtained by using etherdiamine in a concentration range of $250.0-650.0 \mathrm{mg} / \mathrm{L}$. The equilibrium time and $\mathrm{pH}$ value used in these studies were $180 \mathrm{~min}$ and 10 , respectively.

Various isotherm models are available in the literature. Four of the most widely used isotherms were chosen to evaluate the equilibrium adsorption data: the Langmuir (1918), Freundlich (1906), Langmuir-Freundlich (Sips) (Do, 1998), and Temkin and Pyzhev (1940) isotherms.

Eq. (8) is the general form of the Langmuir equation and Eq. (9) is a linearized and rearranged form of the general form of Eq. (8) (Ho et al., 2005).

$$
\begin{aligned}
q_{e} & =\frac{Q_{\max } b C_{e}}{1+b C_{e}} \\
\frac{C_{e}}{q_{e}} & =\frac{1}{Q_{\max } b}+\frac{C_{e}}{Q_{\max }}
\end{aligned}
$$

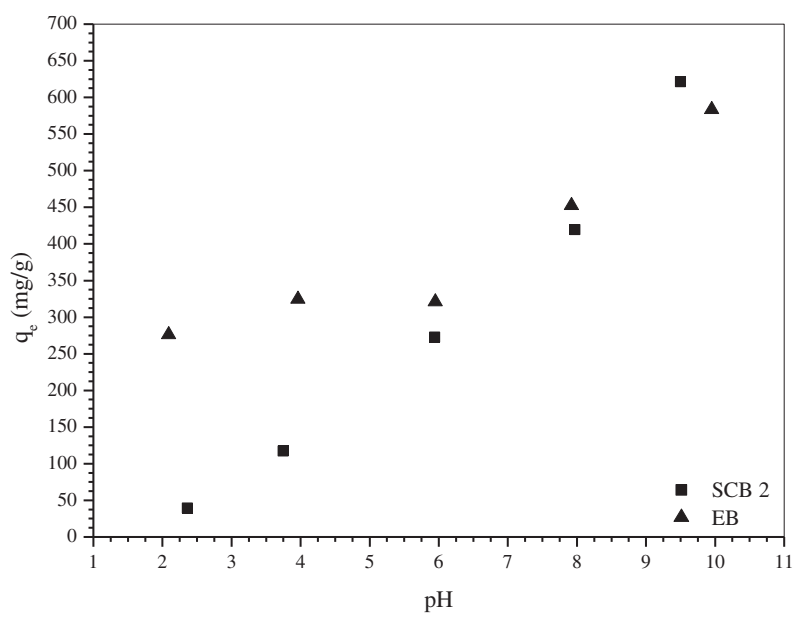

Fig. 4. Effect of pH on the adsorption of etherdiamine on SCB 2 and EB. 
where $q_{e}(\mathrm{mg} / \mathrm{g})$ is the equilibrium adsorption capacity, $Q_{\max }(\mathrm{mg} / \mathrm{g})$ is the maximum adsorption capacity of etherdiamine per unit weight of SCB 2 or EB to form complete monolayer coverage on the surface bound at a high equilibrium etherdiamine concentration $C_{e}$ $(\mathrm{mg} / \mathrm{L})$, and $b(\mathrm{~L} / \mathrm{mg})$ is the Langmuir constant related to the affinity of binding sites. $Q_{\max }$ represents the practical limiting adsorption capacity when the surface is fully covered with etherdiamine. Linearized plots of $C_{e} / q_{e}$ versus $C_{e}$ were obtained from the model and are shown in Fig. 5. $Q_{\max }$ and $b$ were computed from the slopes and intercepts of the straight lines. Table 2 lists the calculated results.

One of the essential characteristics of the Langmuir isotherm can be expressed by a separation factor, $R_{L}$; which is defined using Eq. (10):

$R_{L}=\frac{1}{1+b C_{i}}$

where $C_{i}$ is the initial concentration of the etherdiamine $(\mathrm{mg} / \mathrm{L})$. The value of $R_{L}$ indicates whether an isotherm is irreversible $\left(R_{L}=0\right)$, favorable $\left(0<R_{L}<1\right)$, linear $\left(R_{L}=1\right)$, or unfavorable $\left(R_{L}>1\right)$. The calculated values of $R_{\mathrm{L}}$ for SCB 2 and EB are shown in Table 2. These $R_{L}$ values showed that the adsorption of etherdiamine on both materials was favorable.

The general form of the Freundlich equation can be expressed by Eq. (11). Eq. (12) is the linearized form of Eq. (11):
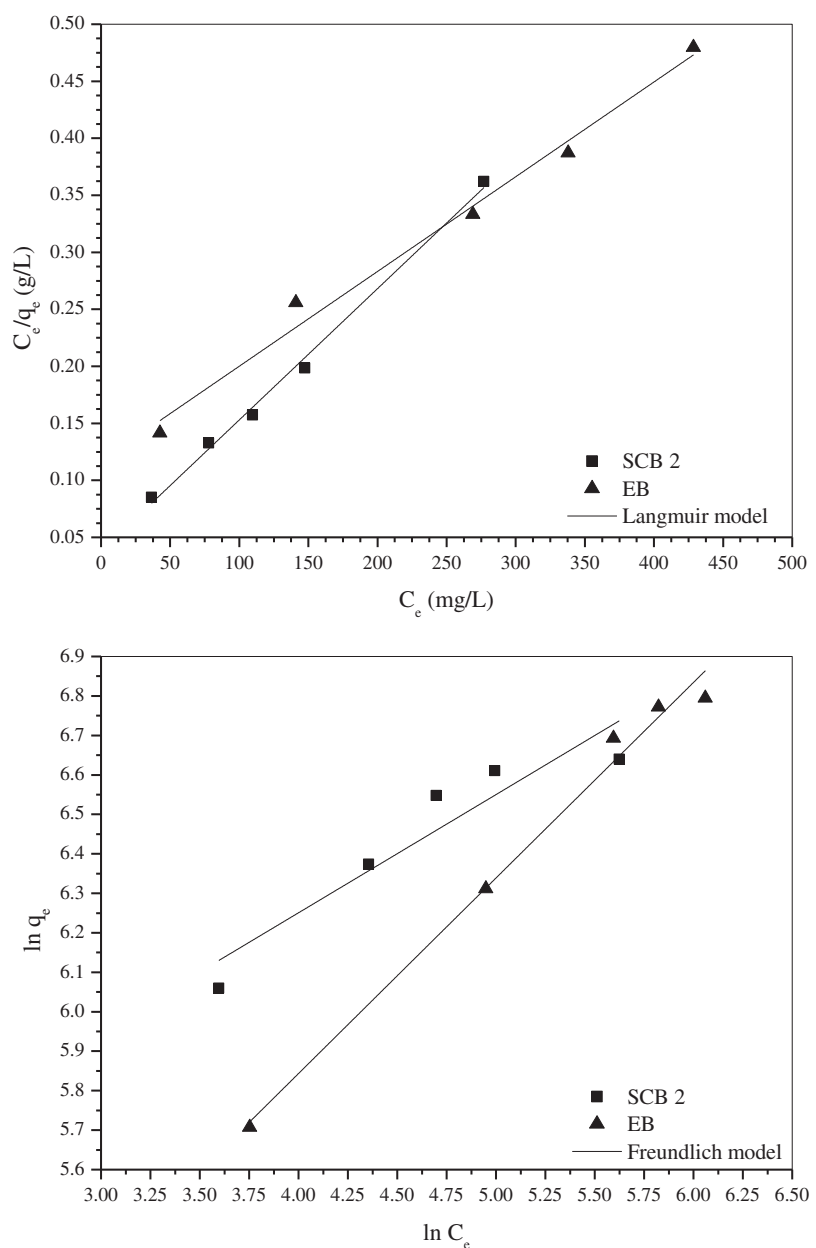

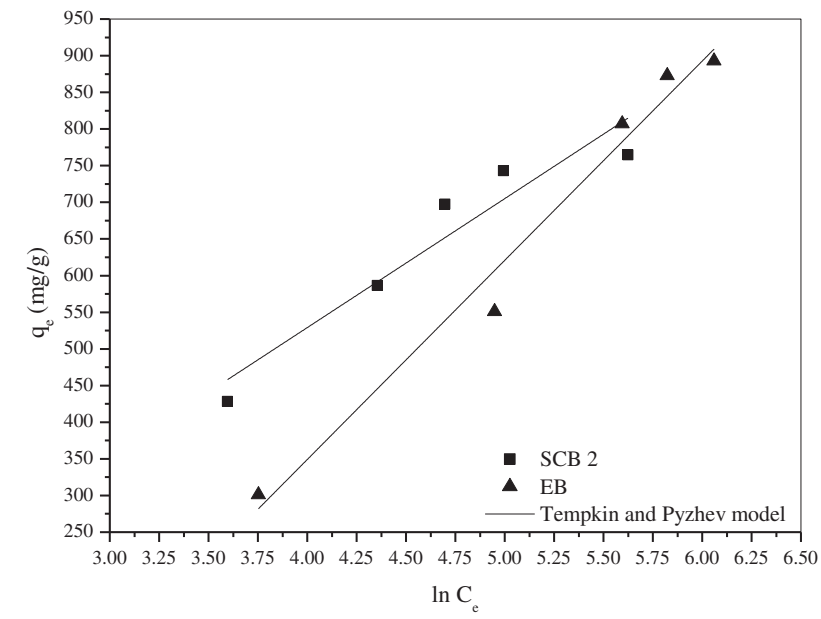

$\ln q_{e}=\ln K+\frac{1}{n} \ln C_{e}$

where $K\left(\mathrm{mg} / \mathrm{g}(\mathrm{L} / \mathrm{mg})^{1 / \mathrm{n}}\right)$ and $n$ are the Freundlich constants. The term $1 / n$ indicates the intensity of adsorption; in other words, the effectiveness of adsorption. Thus, when $1 / n$ is less than unity, adsorption is favorable. Values of $K$ and $n$ are calculated from the intercepts and slopes of the plots of $\ln q_{e}$ versus $\ln C_{e}$ and are also listed in Table 2.

The Temkin isotherm is generally used in the linearized and rearranged form of Eq. (13), as shown in Eq. (14):

$q_{e}=B \ln A C_{e}$

$q_{e}=B \ln A+B \ln C_{e}$

where $A$ is the equilibrium constant of binding corresponding to the maximum energy of binding $(\mathrm{mg} / \mathrm{L})$ and the constant $B$ is related to the heat of adsorption ( $\mathrm{L} / \mathrm{mg})$. A plot of $q_{e}$ versus $\ln C_{e}$ enables the determination of the isotherm constants $A$ and $B$. The values of $A$ and $B$ obtained in this study are shown in Table 2 .

The non-linear form of Langmuir-Freundlich isotherm (Sips isotherm) can be written as Eq. (15):

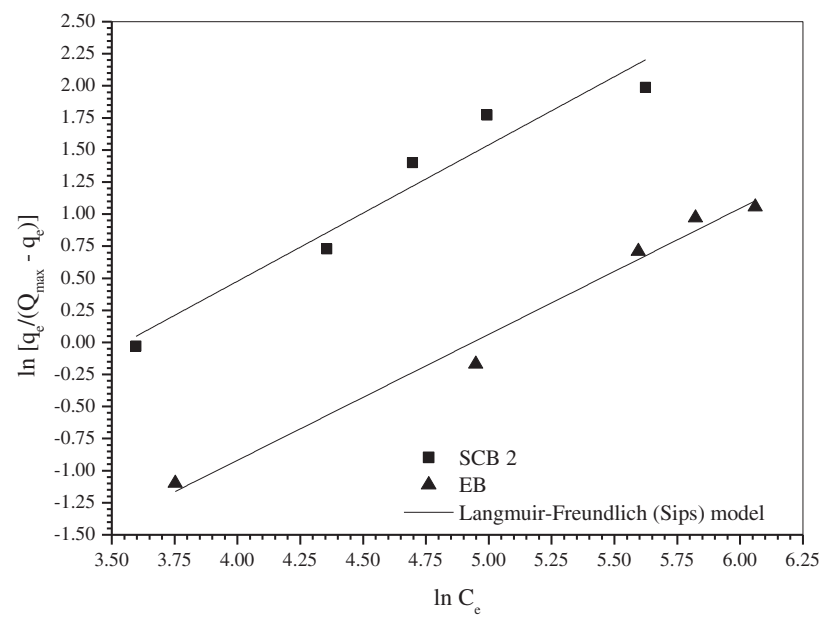

Fig. 5. Isotherm plots for the adsorption of etherdiamine on SCB 2 and EB. 
Table 2

Isotherm parameters for the adsorption of etherdiamine on SCB 2 and EB obtained from linearized models.

\begin{tabular}{|c|c|c|c|c|c|c|c|c|c|c|c|}
\hline \multicolumn{3}{|l|}{ Langmuir } & \multicolumn{3}{|l|}{ Freundlich } & \multicolumn{3}{|l|}{ Temkin } & \multicolumn{3}{|c|}{ Langmuir-Freundlich (Sips) } \\
\hline & SCB 2 & EB & & SCB 2 & EB & & SCB 2 & EB & & SCB 2 & EB \\
\hline$Q_{\max }(\mathrm{mg} / \mathrm{g})$ & 869.6 & 1203.5 & $K\left(\mathrm{mg} / \mathrm{g}(\mathrm{L} / \mathrm{mg})^{1 / \mathrm{n}}\right)$ & 156.5 & 57.0 & $A(\mathrm{mg} / \mathrm{L})$ & 0.37 & 0.065 & $Q_{\max }(\mathrm{mg} / \mathrm{g})$ & 869.6 & 1203.5 \\
\hline$b(\mathrm{~L} / \mathrm{mg})$ & 0.030 & 0.007 & $n$ & 3.34 & 2.12 & $B(\mathrm{~L} / \mathrm{mg})$ & 175.94 & 272.63 & $b(\mathrm{~L} / \mathrm{mg})$ & 0.018 & 0.009 \\
\hline$R^{2}$ & 0.9951 & 0.9919 & $R^{2}$ & 0.8849 & 0.9158 & $R^{2}$ & 0.9085 & 0.9757 & $n$ & 0.94 & 1.02 \\
\hline$R_{L}$ & $0.448-0.107$ & $0.768-0.247$ & - & - & - & - & - & - & $R^{2}$ & 0.9224 & 0.9788 \\
\hline$\Delta G^{o}(\mathrm{~kJ} / \mathrm{mol})^{\mathrm{a}}$ & -22.70 & -19.10 & - & - & - & - & - & - & - & - & - \\
\hline
\end{tabular}

a Molar mass of etherdiamine F 2835 used in free energy calculation was $312.2 \mathrm{~g} / \mathrm{mol}$.

$$
q_{e}=Q_{\max } \frac{\left(b C_{e}\right)^{1 / n}}{1+\left(b C_{e}\right)^{1 / n}}
$$

Eq. (15) can be rearranged and written as follows in linearized form as Eq. (16):

$\ln \left[\frac{q_{e}}{Q_{\max }-q_{e}}\right]=\frac{1}{n} \ln C_{e}+\frac{1}{n} \ln b$

where $Q_{\max }$ is the total number of binding sites $(\mathrm{mg} / \mathrm{g}), b$ is a Sips constant related to the energy of adsorption $(\mathrm{L} / \mathrm{mg})$, and $n$ is the heterogeneity factor. If the parameter $n$ is unity, the Langmuir equation is applicable for ideal surfaces. Hence, the parameter $n$ could be regarded as the parameter characterizing system heterogeneity. System heterogeneity could stem from the adsorbent or the adsorbate or a combination of both. The parameter $n$ is usually greater than unity, and larger value for this parameter indicates a more heterogeneous system. A plot of $\ln \left[\left(q_{e} /\left(Q_{\max }-q_{e}\right)\right]\right.$ versus $\ln$ $C_{e}$ yields $b$ and $n$ from the intercept and slope, respectively. The value of $Q_{\max }$ used in the plot of $\ln \left[\left(q_{e} /\left(Q_{\max }-q_{e}\right)\right]\right.$ versus $\ln C_{e}$ can be obtained from the Langmuir model. The values of $Q_{\max }, b$, and $n$ obtained in this study are shown in Table 2.

The results for each model are presented in Table 2. The determination coefficients, $R^{2}$, were used to compare the four isotherm models. As can be seen from Table 2, the Langmuir model showed a higher determination coefficient than the Freundlich, Sips, and Temkin models. The Langmuir-Freundlich (Sips) model revealed, through $n$ values, that the system composed of etherdiamine-EB was less heterogeneous than etherdiamine-SCB 2 . Furthermore, the $n$ values from the Sips model also suggested that the Langmuir model can describe the adsorption of etherdiamine on SCB 2 and EB very well. Similar results were reported by Magriotis et al. (2010) for the adsorption of etheramine on kaolinites. The $Q_{\max }$ of SCB 2 and EB for etherdiamine adsorption using the Langmuir model were found to be 869.6 and $1203.5 \mathrm{mg} / \mathrm{g}$, respectively. These results are much higher in comparison with $Q_{\max }$ for other adsorbents reported in the literature. For example, the study of adsorption of etheramine Flotigam EDA on kaolinite carried out by Magriotis et al. (2010) revealed $Q_{\max }$ values obtained by the Langmuir model of 33.03, 34.32, and $23.11 \mathrm{mg} / \mathrm{g}$ for white, pink, and yellow kaolinites, respectively. Safa and Bhatti (2011) also studied the adsorption of etheramine Flotigam EDA on kaolinite subjected to acid, thermal, and peroxide treatments and found $Q_{\max }$ values obtained by the Langmuir model of 27, 29, and $59 \mathrm{mg} / \mathrm{g}$, respectively. In addition, the higher adsorption capacity for EB in relation to SCB 2 may be attributed to the presence of amine groups in the EDTA moiety that can probably interact with the amine groups of etherdiamine via the formation of hydrogen bonds. The suggested mechanism of interaction of partially protonated etherdiamine with SCB 2 and EB is shown in Fig. $1 \mathrm{~b}$. The calculated free energy (Table 2) for the adsorption of etherdiamine on SCB $2(-22.70 \mathrm{~kJ} / \mathrm{mol})$ and EB $(-19.10 \mathrm{~kJ} / \mathrm{mol})$ suggests that chemisorption is the main mechanism whereby etherdiamine is removed from the aqueous solution for both adsorbents.

\subsection{Adsorption kinetics}

Kinetic models were used to determine the rate of the adsorption process and how this rate controls the equilibrium time. The adsorption of a solute by a solid support in aqueous solution is a phenomenon with often complex kinetics. The mechanism of adsorption depends on the physical and/or chemical characteristics of the adsorbent as well as on the mass-transport process. In order to investigate the mechanism of etherdiamine adsorption on SCB 2 and $\mathrm{EB}$, three kinetic models were investigated: pseudo-first-order, pseudo-second-order, and Elovich.

The pseudo-first-order kinetic model of Lagergren (1898) shown in Eq. (17) is more suitable for lower concentrations of the solute. Its linear form is shown in Eq. (18):

$q_{t}=q_{e}\left(1-\exp ^{-k_{1} t}\right)$

$\log \left(q_{e}-q_{t}\right)=\log q_{e}-\frac{k_{1}}{2.303} t$

where $q_{t}(\mathrm{mg} / \mathrm{g})$ is the amount of adsorbate adsorbed at time $t$ (min), $q_{e}(\mathrm{mg} / \mathrm{g})$ is the equilibrium adsorption capacity, and $k_{1}$ $\left(\mathrm{min}^{-1}\right)$ is the pseudo-first-order rate constant.

The values of $k_{1}$ and $q_{e}$ for the adsorption of etherdiamine on SCB 2 and EB were determined from the plot of $\log \left(q_{e}-q_{t}\right)$ versus $t$. The obtained straight line yields $k_{1}$ as the slope and $\ln q_{e}$ as the intercept.

The pseudo-second-order model of Ho and McKay (1998) based on adsorption capacity can be represented as Eq. (19) and in the linear form in Eq. (20):

$q_{t}=\frac{k_{2} q_{e}^{2} t}{1+k^{2} q_{e} t}$

$\frac{t}{q_{t}}=\frac{1}{k_{2} q_{e}^{2}}+\frac{1}{q_{e}} t$

where $q_{e}(\mathrm{mg} / \mathrm{g})$ and $q_{t}(\mathrm{mg} / \mathrm{g})$ are the solute amounts adsorbed per unit weight of the adsorbent at equilibrium time and at time $t$ (min) and $k_{2}$ is the pseudo-second-order rate constant $\left(\mathrm{g} \mathrm{mg}^{-1} \mathrm{~min}^{-1}\right)$. The parameters from the pseudo-second-order model, $k_{2}$ and $q_{e}$, can be obtained from the slope and intercept of the plot of $t / q_{t}$ versus $t$ (Fig. 6).

The Elovich model suggests that chemisorption, i.e. a chemical reaction, is probably the mechanism that controls the rate of adsorption (Crini and Badot, 2008). This model can be applied with success in liquid solution. The linear form of the Elovich equation is shown in Eq. (21): 


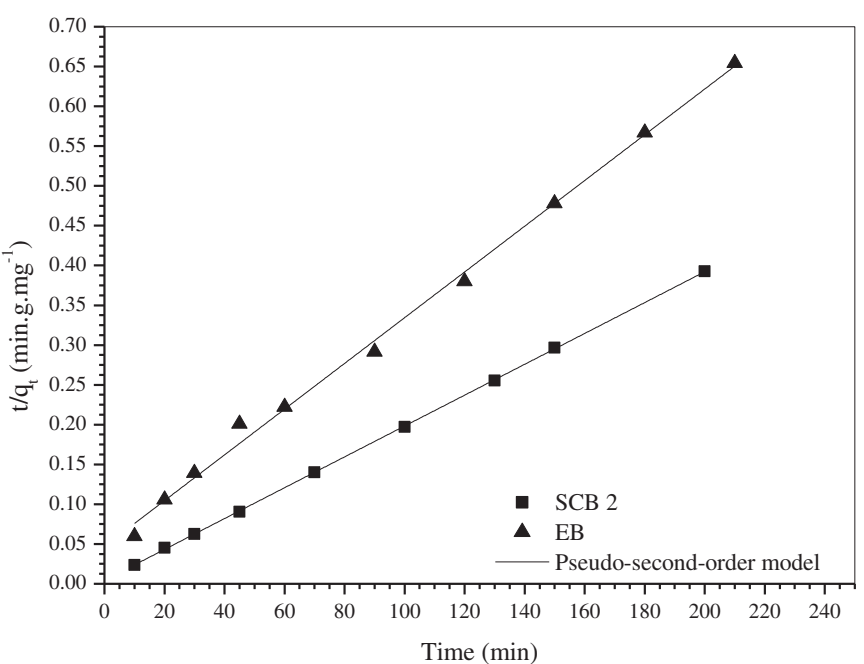

Fig. 6. Linearized pseudo-second-order kinetic plot for the adsorption of etherdiamine on SCB 2 and EB.

$q_{t}=\frac{1}{\beta} \ln \alpha \beta+\frac{1}{\beta} \ln t$

where $\alpha(\mathrm{mg} / \mathrm{g} \mathrm{min})$ is the initial sorption rate and $\beta(\mathrm{g} / \mathrm{mg})$ is the desorption constant.

The values of $\alpha$ and $\beta$ can be calculated from the slope and intercept of the plot of $q_{t}$ versus $\ln t$ that yields a straight line. Table 3 lists the calculated results for the three models.

As can be seen in Table 3, the values of $R^{2}$ are closer to unity for the pseudo-second-order model than the pseudo-first-order model and Elovich model. Thus, the pseudo-second-order model can describe etherdiamine adsorption by both materials very well. Furthermore, values of $q_{e \text {,cal }}$ calculated from the pseudo-secondorder model were in good agreement with the experimental values, $q_{e, \text { exp }}$, compared to those calculated from the pseudo-firstorder model. The adsorption phenomenon followed the pseudosecond-order model during the entire period of adsorption and thus supports the model presupposition that adsorption is controlled by a chemical process, i.e. chemisorption (Crini and Badot, 2008). Similar results were reported for the adsorption of etheramine on kaolinites by Magriotis et al. (2010).

\subsection{Extraction process of etherdiamine}

The high adsorption capacity values found for SCB 2 and EB exemplify the great potential of these adsorbent materials to treat effluents from the flotation of iron ore. Due to the high cost of etherdiamine, the recovery of such important chemical compound is economically important. The percentages of etherdiamine extracted and recovered from SCB 2 and EB were 63\% and 65\%, respectively. These results revealed that there is the possibility of recycling SCB 2 and EB for subsequent adsorption experiments even though the adsorption capacity is lower than in the first cycle of adsorption.

\subsection{Scanning electron microscopy}

SEM is widely used to study the morphological features and surface characteristics of various adsorbent materials (Namasivayam and Kavitha, 2006). SEM micrographs can also used to assess morphological changes in the fiber surfaces following the adsorption of etherdiamine (Flotigam 2835) on SCB 2 and EB adsorbents.
Table 3

Kinetic parameters for the adsorption of etherdiamine on SCB 2 and EB.

\begin{tabular}{|c|c|c|}
\hline & SCB 2 & EB \\
\hline & $q_{e . \exp }(\mathrm{mg} / \mathrm{g}) 509.47$ & $q_{e . \exp }(\mathrm{mg} / \mathrm{g}) 320.90$ \\
\hline \multicolumn{3}{|c|}{ Pseudo-first-order } \\
\hline$k_{1}\left(\min ^{-1}\right)$ & 0.026 & 0.031 \\
\hline$q_{e, \text { calc }}(\mathrm{mg} / \mathrm{g})$ & 66.35 & 281.16 \\
\hline$R^{2}$ & 0.8405 & 0.8991 \\
\hline \multicolumn{3}{|c|}{ Pseudo-second-order } \\
\hline$k_{2}(\mathrm{~g} / \mathrm{mg} \min )$ & 0.00086 & 0.00017 \\
\hline$q_{e, \text { calc }}(\mathrm{mg} / \mathrm{g})$ & 515.46 & 348.43 \\
\hline$R^{2}$ & 0.9998 & 0.9966 \\
\hline \multicolumn{3}{|c|}{ Elovich equation } \\
\hline$\alpha(\mathrm{mg} / \mathrm{g} \min )$ & $8.42 \times 10^{6}$ & 90.11 \\
\hline$\beta(\mathrm{g} / \mathrm{mg})$ & 0.034 & 0.017 \\
\hline$R^{2}$ & 0.8664 & 0.9469 \\
\hline
\end{tabular}

\subsubsection{Morphology of unloaded adsorbents}

Fig. 7a and b shows SEM micrographs of SCB 2 and EB adsorbents before adsorption of etherdiamine at 300 times of magnification, respectively. The adsorbents have a great variety of shapes and sizes, characterizing the great heterogeneity of the sugarcane bagasse after the milling process. Supplementary Fig. 3a and b shows micrographs of SCB 2 and EB adsorbents with magnification of 2000 times. In these micrographs is possible to see that both adsorbent fibers present pores and cracks on their surfaces.

\subsubsection{Morphology of loaded adsorbents}

Fig. 7c and d shows SEM micrographs of SCB 2 and EB adsorbents after adsorption of etherdiamine at 300 times of magnification, respectively. The morphology of the loaded adsorbents showed some important observations. The surface coverage of the adsorbents due to adsorption of etherdiamine molecules led to the formation of a monolayer of etherdiamine molecules over the surface of SCB 2 and EB. SEM micrographs of SCB 2 and EB surfaces covered with etherdiamine were found to be smooth in relation to unloaded adsorbent materials due to formation of a layer (molecular cloud) of uniform thickness (Safa and Bhatti, 2011) (see Fig. 7). Other differences in morphology can also be examined in supplementary Fig. 3c and d that shows micrographs of SCB 2 and EB adsorbents after adsorption with magnification of 2000 times.

\subsection{Advantages and disadvantages of the proposed method}

Etherdiamine is an expensive chemical of great importance in iron ore flotation and concentration processes. It is estimated that approximately 6000 tons of fatty amines derivatives are used annually in Brazil for iron ore flotation processes (Rocha et al., 2013). According to Rocha et al. (2013), the Samarco company mining plant uses about 1500 tons of etherdiamine per year in order to produce 16 million tons of concentrate per year, representing close to $50 \%$ of the overall costs in 2006 (Rocha et al., 2013). Therefore, a process for the recovery and reuse of the etherdiamine is strongly desired. Biodegradation of fatty amines as an alternative process to eliminate these compounds from the effluent once they become very toxic was proposed by Araujo et al. (2010). This method has great advantages for eliminating the problem of toxicity of fatty amines through their degradation to non-toxic compounds. However, the drawback in this case is the fact that once the amines are degraded, there arises the need for addition of more fatty amines to the flotation process, which increases the overall costs. The method proposed in this study avoids this limitation by removing large amounts of etherdiamine and furthermore the etherdiamine adsorbed on SCB 2 and EB can be extracted, recovered, and reused in the flotation process. The major 

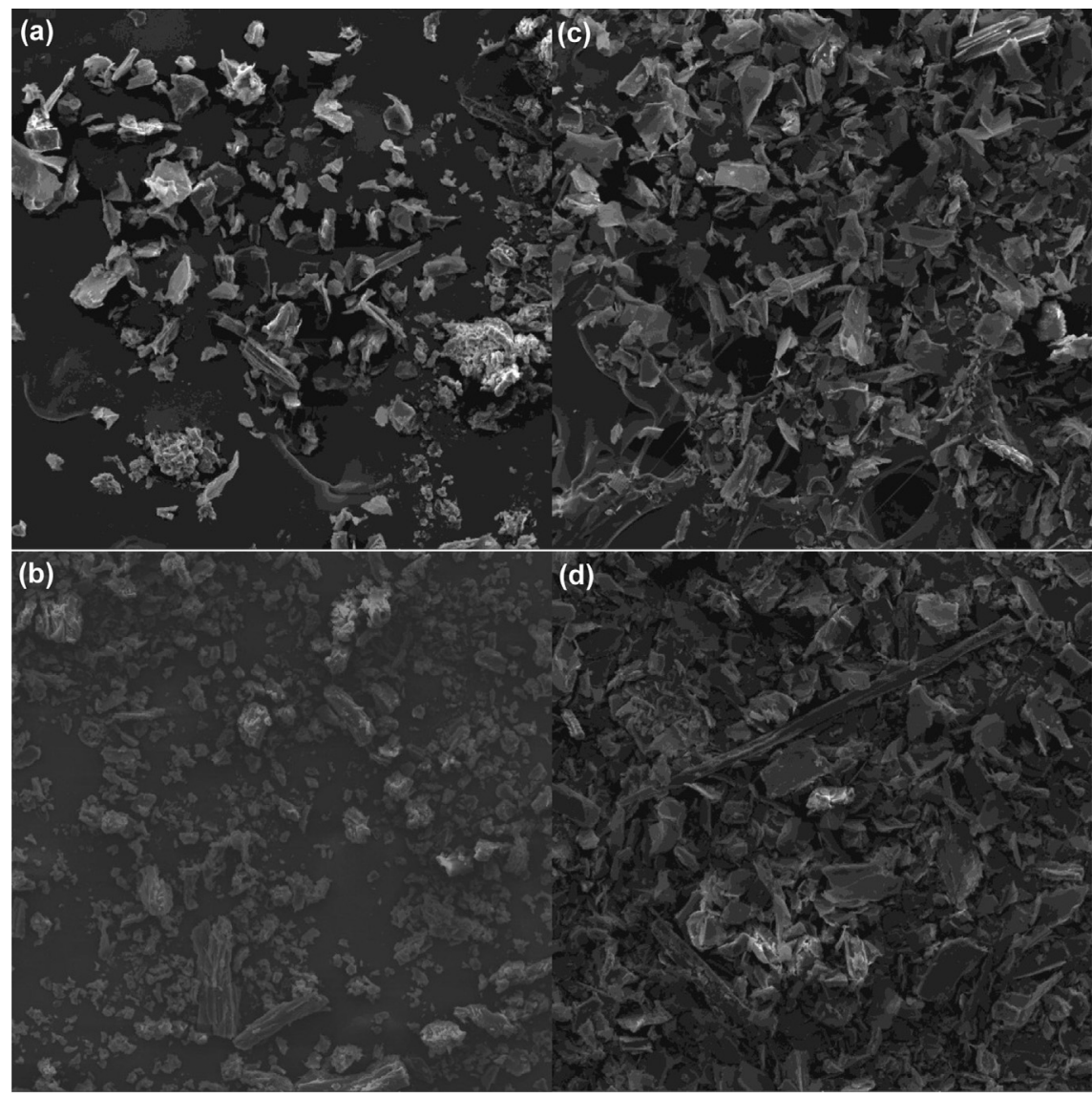

Fig. 7. SEM micrographs of unloaded (a) and (b) and etherdiamine-loaded (c) and (d) SCB 2 and EB (300×).

disadvantage of the proposed method is that only $63-65 \%$ of etherdiamine can extracted and recovered from SCB 2 and EB, respectively.

\section{Conclusion}

The materials modified with succinic anhydride (SCB 2) and EDTA dianhydride (EB), prepared from sugarcane bagasse, an important agricultural waste, were shown to be very efficient in removing, by adsorption, etherdiamine Flotigam 2835, used in the reverse flotation of iron ore from aqueous solutions. The adsorption of etherdiamine attained equilibrium after $90 \mathrm{~min}$ and it was favored at $\mathrm{pH}$ 10.0. The results of equilibrium adsorption were evaluated by four adsorption models and the experimental data fitted very well to the Langmuir model. $Q_{\max }$ of SCB 2 and EB for etherdiamine adsorption using the Langmuir model were found to be 869.6 and $1203.5 \mathrm{mg} / \mathrm{g}$, respectively. These $Q_{\max }$ values are much higher in comparison with other results reported in the literature. Three kinetic models were used to model the kinetics of adsorption. The adsorption process was well-described by the pseudo-secondorder model. Extraction process showed that the percentages of etherdiamine recovered from SCB 2 and EB were 63\% and 65\%, respectively.

\section{Acknowledgments}

The authors are grateful to Universidade Federal de Ouro Preto (UFOP), FAPEMIG, CNPq and CAPES for funding this research. Authors would also like to thank Dr. Jason G. Taylor (UFOP) for reviewing the manuscript for its English usage. The authors are also grateful to Laboratório de Microscopia Eletrônica, microanálises e caracterização de materiais (NanoLab/FINEP - Redemat, Escola de Minas, UFOP) and B.S. Ney P. Sampaio for SEM analyses.

\section{Appendix A. Supplementary data}

Supplementary data related to this article can be found at http:// dx.doi.org/10.1016/j.jenvman.2013.11.040.

\section{References}

Alves, F., 2006. Minério de ferro. Rev. Brasil Miner. 255, 14-20.

Araujo, A.C., Viana, P.R.M., Peres, A.E.C., 2005. Reagents in iron ores flotation. Miner Eng. 18, 219-224.

Araujo, D.M., Yoshida, M.I., Carvalho, C.F., Stapelfeldt, F., 2008. Recycling of amines present in the residues from the reverse flotation of iron ore. Rem.-Rev. Esc. Minas. 61, 455-460.

Araujo, D.M., Yoshida, M.I., Takahashi, J.A., Carvalho, C.F., Stapelfeldt, F., 2010. Biodegradation studies on fatty amines used for reverse flotation of iron ore. Int. Biodeterior. Biodegrad. 64, 151-155.

Caraschi, J.C., Filho, S.P.C., Curvelo, A.A.S., 1996. Preparação e caracterização de polpas para dissolução obtidas a partir de bagaço de cana-de-açúcar. Polímer. Ciênc. Tecnol. 6, 24-29.

Clesceri, L.S., Eaton, A.D., Greenberg, A.E., Franson, M.A.H., Association, A.P.H., Association, A.W.W., Federation, W.E., 1995. Standard Methods for the Examination of Water and Wastewater, nineteenth ed. American Public Health Association, Washington.

CONAB, 2011. Companhia Nacional de Abastecimento. Avaliação da safra agrícola brasileira de cana-de-açúcar. Safra 2011/2012, terceiro levantamento, Dezembro (in Portuguese).

Crini, G., 2006. Non-conventional low-cost adsorbents for dye removal: a review. Bioresour. Technol. 97, 1061-1085.

Crini, G., Badot, P.M., 2008. Application of chitosan, a natural aminopolysaccharide, for dye removal from aqueous solutions by adsorption processes using batch studies: a review of recent literature. Prog. Polym. Sci. 33, 399-447.

Dean, J.A., Lange, N.A., 1999. Handbook of Chemistry. McGraw-Hill. 
Do, D., 1998. Adsorption Analysis: Equilibria and Kinetics. Imperial College Press.

Filippov, L.O., Filippova, I.V., Severov, V.V., 2010. The use of collectors mixture in the reverse cationic flotation of magnetite ore: the role of Fe-bearing silicates. Miner. Eng. 23, 91-98.

Freundlich, H.M.F., 1906. Over the adsorption in solution. Z. Physikal. Chem. 57A, $385-470$.

Gupta, V.K., Suhas, 2009. Application of low-cost adsorbents for dye removal - a review. J. Environ. Manage. 90, 2313-2342.

Gurgel, L.V.A., de Freitas, R.P. Gil, L.F., 2008. Adsorption of $\mathrm{Cu}(\mathrm{II}), \mathrm{Cd}(\mathrm{II})$, and $\mathrm{Pb}(\mathrm{II})$ from aqueous single metal solutions by sugarcane bagasse and mercerized sugarcane bagasse chemically modified with succinic anhydride. Carbohyd. Polym. 74, 922-929.

Gurgel, L.V.A., Gil, L.F., 2009. Adsorption of $\mathrm{Cu}(\mathrm{II}), \mathrm{Cd}(\mathrm{II})$ and $\mathrm{Pb}(\mathrm{II})$ from aqueous single metal solutions by succinylated twice-mercerized sugarcane bagasse functionalized with triethylenetetramine. Water Res. 43, 4479-4488.

Gusmao, K.A.G., Gurgel, L.V.A., Melo, T.M.S., Gil, L.F., 2012. Application of succinylated sugarcane bagasse as adsorbent to remove methylene blue and gentian violet from aqueous solutions - kinetic and equilibrium studies. Dyes Pigm. 92, 967-974.

Ho, Y.S., Chiu, W.T., Wang, C.C., 2005. Regression analysis for the sorption isotherms of basic dyes on sugarcane dust. Bioresour. Technol. 96, 1285-1291.

Ho, Y.S., McKay, G., 1998. Kinetic models for the sorption of dye from aqueous solution by wood. Process. Saf. Environ. 76, 183-191.

Karnitz, O., Gurgel, L.V.A., de Freitas, R.P., Gil, L.F., 2009. Adsorption of Cu(II), Cd(II), and $\mathrm{Pb}(\mathrm{II})$ from aqueous single metal solutions by mercerized cellulose and mercerized sugarcane bagasse chemically modified with EDTA dianhydride (EDTAD). Carbohyd. Polym. 77, 643-650.

Karnitz, O., Gurgel, L.V.A., de Melo, J.C.P., Botaro, V.R., Melo, T.M.S., Gil, R.P.D.F., Gil, L.F., 2007. Adsorption of heavy metal ion from aqueous single metal solution by chemically modified sugarcane bagasse. Bioresour. Technol. 98, 1291-1297.

Karnitz, O., Gurgel, L.V.A., Gil, L.F., 2010. Removal of $\mathrm{Ca}(\mathrm{II})$ and $\mathrm{Mg}(\mathrm{II})$ from aqueous single metal solutions by mercerized cellulose and mercerized sugarcane bagasse grafted with EDTA dianhydride (EDTAD). Carbohydr. Polym. 79, 184191.

Kumar, U., 2006. Agricultural products and by-products as a low cost adsorbent for heavy metal removal from water and wastewater: a review. Sci. Res. Essays 1, $33-37$.

Lagergren, S., 1898. Zur Theorie der sogenannten adsorption gelöster stoffe. K. Svenska Vetenskapsakad. Handl. 24, 1-39.

Langmuir, I., 1918. The adsorption of gases on plane surfaces of glass, mica and platinum. J. Am. Chem. Soc. 40, 1361-1403.

Leja, J., 1982. Surface Chemistry of Froth Flotation, second ed. Plenum Press, New York.
Lima, R.M.F., Brandao, P.R.G., Peres, A.E.C., 2005. The infrared spectra of amine collectors used in the flotation of iron ores. Miner. Eng. 18, 267-273.

Liu, Y., 2009. Is the free energy change of adsorption correctly calculated? J. Chem. Eng. Data. 54, 1981-1985.

Magriotis, Z.M., Leal, P.V.B., Sales, P.F., Papini, R.M., Viana, P.R.M., 2010. Adsorption of etheramine on kaolinite: a cheap alternative for the treatment of mining effluents. J. Hazard. Mater. 184, 465-471.

Namasivayam, C., Kavitha, D., 2006. IR, XRD and SEM studies on the mechanism of adsorption of dyes and phenols by coir pith carbon from aqueous phase. Microchem. J. 82, 43-48.

Navarro, R.R., Sumi, K., Fujii, N., Matsumura, M., 1996. Mercury removal from wastewater using porous cellulose carrier modified with polyethyleneimine. Water Res. 30, 2488-2494.

Ngah, W.S.W., Hanafiah, M.A.K.M., 2008. Removal of heavy metal ions from wastewater by chemically modified plant wastes as adsorbents: a review. Bioresour. Technol. 99, 3935-3948.

Noh, J.S., Schwarz, J.A., 1990. Effect of $\mathrm{HNO}_{3}$ treatment on the surface-acidity of activated carbons. Carbon 28, 675-682.

Pearse, M.J., 2005. An overview of the use of chemical reagents in mineral processing. Miner. Eng. 18, 139-149.

Pereira, F.V., Gurgel, L.V.A., de Aquino, S.F., Gil, L.F., 2009. Removal of $\mathrm{Zn}^{2+}$ from electroplating wastewater using modified wood sawdust and sugarcane bagasse. J. Environ. Eng.-ASCE 135, 341-350.

Pereira, F.V., Gurgel, L.V.A., Gil, L.F., 2010. Removal of $\mathrm{Zn}^{2+}$ from aqueous single metal solutions and electroplating wastewater with wood sawdust and sugarcane bagasse modified with EDTA dianhydride (EDTAD). J. Hazard. Mater. 176, 856-863.

Rocha, G.M., Silva, V.N., Martín, C., Gonçalves, A., Nascimento, V., Souto-Maior, A. 2013. Effect of xylan and lignin removal by hydrothermal pretreatment on enzymatic conversion of sugarcane bagasse cellulose for second generation ethanol production. Sugar Tech., 1-9.

Safa, Y., Bhatti, H.N., 2011. Kinetic and thermodynamic modeling for the removal of Direct Red-31 and Direct Orange-26 dyes from aqueous solutions by rice husk. Desalination 272, 313-322.

Scott, J.L., Smith, R.W., 1991. Diamine flotation of quartz. Miner. Eng. 4, 141-150.

Temkin, M.J., Pyzhev, V., 1940. Kinetics of ammonia synthesis on promoted iron catalysts. Acta Physiochim. U.R.S.S 12, 217-222.

Teodoro, A.L., Leão, V.A., 2004. Recuperação de aminas, utilizadas na flotação de minério de ferro, utilizando-se zeólitas naturais. Rev. Escola Minas. 57, 197-201.

Xiao, B., Sun, X.F., Sun, R.C., 2001. The chemical modification of lignins with succinic anhydride in aqueous systems. Polym. Degrad. Stabil. 71, 223-231.

Xing, Y., Deng, D.H., 2009. Enhanced adsorption of Malachite Green by EDTADmodified sugarcane bagasse. Sep. Sci. Technol. 44, 2117-2131. 